Article

\title{
Genome-Wide Identification and Characterization of the Trehalose-6-Phosphate Synthetase (TPS) Gene Family in Watermelon (Citrullus lanatus) and Their Transcriptional Responses to Salt Stress
}

\author{
Gaopeng Yuan, Junpu Liu, Guolin An, Weihua Li, Wenjing Si, Dexi Sun * and Yingchun Zhu *
}

check for updates

Citation: Yuan, G.; Liu, J.; An, G.; Li, W.; Si, W.; Sun, D.; Zhu, Y. Genome-Wide Identification and

Characterization of the

Trehalose-6-Phosphate Synthetase (TPS) Gene Family in Watermelon (Citrullus lanatus) and Their Transcriptional Responses to Salt

Stress. Int. J. Mol. Sci. 2022, 23, 276

https://doi.org/10.3390/ijms 23010276

Academic Editor: Richard R.-C. Wang

Received: 22 November 2021 Accepted: 25 December 2021 Published: 28 December 2021

Publisher's Note: MDPI stays neutral with regard to jurisdictional claims in published maps and institutional affiliations.

Copyright: (C) 2021 by the authors. Licensee MDPI, Basel, Switzerland. This article is an open access article distributed under the terms and conditions of the Creative Commons Attribution (CC BY) license (https:// creativecommons.org/licenses/by/ $4.0 /)$

\author{
Zhengzhou Fruit Research Institute of the Chinese Academy of Agricultural Sciences, Zhengzhou 450000, China; \\ yuangaopeng@caas.cn (G.Y.); liujunpu@caas.cn (J.L.); anguolin@caas.cn (G.A.); liweihua@caas.cn (W.L.); \\ siwenjingsmile@sina.cn (W.S.) \\ * Correspondence: sundexi@caas.cn (D.S.); zhuyingchun@caas.cn (Y.Z.)
}

\begin{abstract}
With the increase in watermelon cultivation area, there is an urgent need to explore enzymatic and genetic resources for the sustainable development of watermelon, especially under salt stress. Among the various compounds known, trehalose plays an important role in regulating abiotic stress tolerances in diverse organisms, including plants. Therefore, the present study comprehensively analyzed the trehalose-6-phosphate synthase (TPS) gene family in watermelon. The study analyzed the functional classification, evolutionary characteristics, and expression patterns of the watermelon TPS genes family. Seven CITPSs were identified and classified into two distinct classes according to gene structure and phylogeny. Evolutionary analysis suggested the role of purifying selection in the evolution of the TPS family members. Further, cis-acting elements related to plant hormones and abiotic stress were identified in the promoter region of the TPS genes. The tissue-specific expression analysis showed that CITPS genes were widely expressed in roots, stems, leaves, flowers, and fruits, while CITPS3 was significantly induced under salt stress. The overexpression of ClTPS3 in Arabidopsis thaliana significantly improved salt tolerance. Finally, the STRING functional protein association networks suggested that the transcription factor CIMYB and ClbHLH regulate ClTPS3. Thus, the study indicates the critical role of CITPS3 in watermelon response to salt stress.
\end{abstract}

Keywords: gene family; watermelon; trehalose-6-phosphate synthetase; salt stress

\section{Introduction}

Trehalose ( $\alpha$-D-glucopyranosyl-1, 1- $\alpha$-D-glucopyranoside) is a non-reducing disaccharide consisting of two glucose molecules linked by $\alpha, \alpha, 1,1$-glycosidic bonds [1]. It has a symmetrical structure, with two glucose molecules having symmetry more stable than maltose, sucrose, glucose, and other sugars of small molecules [2,3]. Therefore, the physical and chemical properties of trehalose are different from its analogs, making it an important component in keeping cells alive. Trehalose is known as a living substance, which exists in all living organisms and plays a major role in plant growth and development $[4,5]$. In recent years, trehalose has attracted extensive attention as a potential signal metabolite and a cell stabilizer of plants. Cells exposed to high temperature, freezing temperature, radiation, drought, high osmotic pressure, high salinity, and other adverse environmental conditions synthesize trehalose in large quantities, which plays an important role in maintaining osmotic pressure, protecting membrane structure, and participating in the signal transduction process. Subsequently, once the crisis is resolved, trehalose decomposes rapidly to substances that act as energy sources [2].

Trehalose in plants was first identified in Selaginella lepidophylla (Hook. and Grev.) Spring almost 100 years ago. A previous study found that high trehalose levels in Selaginella helped it to survive under an extreme drought environment [3]. However, 
in Arabidopsis thaliana and other drought-resistant species, only a small amount of trehalose was detected despite the existence of multiple genes encoding trehalose, which may be related to the co-involvement of its precursor trehalose-6-phosphate (T6P) in the regulation of plant stress [6,7]. These earlier findings suggested that trehalose metabolism regulates the biotic and abiotic stress response and may be an important target for improving the stress tolerance of plants.

The T6P signaling pathway may directly regulate many physiological plant activities, such as seed germination, seedling growth, flowering, and senescence [8-10]. In plants, T6P is mainly present in the cytoplasm and also in vacuoles and chloroplasts in small amounts. During metabolism, uridine diphosphate glucose (UDPG) and 6-phosphate glucose (G6P) are catalyzed by trehalose-6-phosphate synthetase (TPS) to T6P, and T6P is further catalyzed by trehalose-6-phosphate phosphatase (TPP) to trehalose. Finally, trehalase (TRE) catalyzes the conversion of trehalose to two glucose molecules [11]. In the above metabolic pathway, the TPS protein encoded by the TPS gene is the synthetase that catalyzes T6P. TPS genes have been identified in different plants, for example, there are eleven TPS members in A. thaliana, eleven in rice, twelve in poplar, eight in potato, fourteen in rubber tree, twelve in winter wheat, thirteen in apple, twelve in corn, nine in sugarcane, seven each in melon and cucumber, and twenty in soybean $[12,13]$.

Generally, plants have low trehalose content; however, overexpression of the TPS gene will increase the trehalose content and improve stress tolerance [14-16]. Transgenic plants overexpressing the TPS gene improved water-holding power and electrolyte leakage under drought stress [17]. Guo et al. found that the transgenic tobacco line overexpressing AtTPS showed a higher trehalose level and enhanced salt tolerance [18]. The overexpression of HbTPS1 from Pará rubber tree in A. thaliana improved tolerance to freezing, heat, and drought stresses [19]. The drought-resistant transgenic plants obtained by homologous transformation of maize ZmTPS showed better drought tolerance than the control plants under greenhouse conditions [20]. Meanwhile, exogenous trehalose avoided biofilm damage under extreme conditions, such as low temperature, water loss, hyperosmotic stress, and nutritional imbalance [21,22]. In addition, exogenous trehalose increased the chlorophyll content of flue-cured tobacco seedlings under a low nitrogen environment $[23,24]$, significantly alleviated leaf wilting caused by low temperature, increased antioxidant enzyme activities, reduced membrane lipid peroxidation caused by low temperature, increased leaf water content, and promoted osmotic regulatory substances accumulation $[25,26]$. Meanwhile, trehalose regulated the root physiological level, improved tolerance, and promoted root growth and biomass increase in maize seedlings under low-temperature stress [27]. In addition, exogenous trehalose pretreatment significantly alleviated the growth state of watermelon cells under mannitol osmotic stress [28]. The application of exogenous trehalose enhanced the drought tolerance and alleviated the drought damage; trehalose upregulated the activities of antioxidant enzymes, such as superoxide dismutase (SOD), ascorbic acid peroxidase (APX), peroxidase (POD), and catalase (CAT) in the roots and leaves of waxy maize seedlings, reducing the production rate of superoxide anion $\left(\mathrm{O}_{2}{ }^{-}\right)$ and the content of malondialdehyde (MDA) and proline (PRO) [29]. Studies have also shown that trehalose improves salt tolerance by increasing reactive oxygen species (ROS) scavenging capacity, alleviating plasma membrane damage, and maintaining cytoplasmic ion homeostasis $[30,31]$. Similarly, the application of exogenous trehalose promoted the growth of licorice seedlings and the accumulation of effective components under $\mathrm{NaCl}$ stress [32]. In wheat seedlings, exogenous trehalose improved the adaptation to salt stress by increasing proline accumulation and $\mathrm{K}^{+}$absorption [33]. Additionally, Hu et al. showed that an appropriate concentration of trehalose simultaneously improved salt tolerance, drought tolerance, and cold tolerance of cucumber seedlings [34,35].

Watermelon (Citrullus lanatus) is an important economic horticultural crop worldwide. In 2019, watermelon ranked second and seventh in production and cultivated area among the world's top ten fruits. Meanwhile, China is the world's largest watermelon producing and consuming country, and the watermelon industry has played a significant role in 
increasing farmers' income in China. However, soil salinization is a major problem affecting the production and quality of watermelon. According to survey statistics, about one billion $\mathrm{hm}^{2}$ of land worldwide is affected by salinization [36]. It is estimated that more than $50 \%$ of the global arable land area will be salinized by 2050 [37]. The area of salinized soil in China is thirty-six million $\mathrm{hm}^{2}$, accounting for $4.88 \%$ of the available land area, mainly distributed in the north and the coastal regions [38,39]. Studies have shown that most plants are damaged in soils with a salt content of up to $0.3 \%$ [40]. Salt stress mainly inhibits plant growth. However, with the aggravation of salt stress, the leaf area stops increasing, and the aboveground and underground fresh and dry weight decreases significantly [41]. Salt stress can either directly inhibit plant growth or indirectly affect plant growth by inhibiting photosynthesis and reducing the synthesis of growth substances. Moreover, the higher the salt concentration, the longer the action time, and the more noticeable the inhibition effect [42]. For watermelon, salt stress decreases planting area, yield, and quality [43]. Furthermore, with the annual expansion of the watermelon cultivation area, soil salinization will become more serious, which will have a serious impact on the sustainable and healthy development of watermelon.

Therefore, the present study investigated the functional classification, evolutionary characteristics, and expression profile of the CITPS family. The study on the CITPS gene will help breeders effectively select high-quality salt-tolerant germplasm resources to maintain watermelon production under adverse conditions. The study will also be of great significance for the transformation and utilization of saline-alkali land and the improvement of agricultural production levels.

\section{Results}

\subsection{Identification of Watermelon TPS Genes and Distribution of TPS Proteins in Plant}

Research has shown that TPS proteins contain two conserved domains, TPS and TPP $[13,44]$. Seven CITPSs were identified from the watermelon genome database $\mathrm{Cu}$ GenDB (http:/ / cucurbitgenomics.org/organism/21) (accessed on 20 Octomber 2021) by BLASTP and numbered from CITPS1 to CITPS7 depending on their location on the chromosome (Table 1). The length of most of these TPS proteins $(71.4 \%)$ ranged from 831 to 860 amino acids (aa), while the largest TPS (CITPS2) had 933 aa and the smallest (CITPS1) had 831 aa. The molecular weight (MW) ranged from 94.10 to $105.37 \mathrm{kDa}$ and the predicted isoelectric points (pI) from 5.57 to 6.46. Finally, subcellular localization prediction indicated that the seven CITPS proteins were located in the vacuole, including four showing chloroplast localization (CITPS1, CITPS4, CITPS 6, and CITPS7) and two showing cytoplasm localization (CITPS2 and CITPS3) too.

Table 1. Characteristics of TPS family members in watermelon.

\begin{tabular}{|c|c|c|c|c|c|c|c|c|}
\hline $\begin{array}{l}\text { Gene } \\
\text { Name }\end{array}$ & $\begin{array}{l}\text { Gene } \\
\text { ID }\end{array}$ & $\begin{array}{l}\text { Length ORF } \\
\text { (bp) }\end{array}$ & $\begin{array}{l}\text { No. of } \\
\text { Amino } \\
\text { Acids }\end{array}$ & $\begin{array}{c}\text { TPS } \\
\text { Domain } \\
\text { Location }\end{array}$ & $\begin{array}{c}\text { TPP } \\
\text { Domain } \\
\text { Location }\end{array}$ & $\begin{array}{l}\text { Isoelectronic } \\
\text { Point } \\
(p I)\end{array}$ & $\begin{array}{l}\text { Molecular } \\
\text { Mass } \\
\text { (kD) }\end{array}$ & $\begin{array}{l}\text { Subcellular } \\
\text { Localization }\end{array}$ \\
\hline ClTPS1 & Cla97C01G023850.1 & 2496 & 831 & $41-525$ & $574-808$ & 5.57 & 94.10 & Chloroplast/Vacuole \\
\hline CITPS2 & Cla97C03G058540.1 & 2802 & 933 & $92-559$ & $593-817$ & 6.46 & 105.37 & Cytoplasm/Vacuole \\
\hline CITPS3 & Cla97C05G107320.1 & 2583 & 860 & $58-545$ & $594-828$ & 6.15 & 97.32 & Cytoplasm/Vacuole \\
\hline CITPS4 & Cla97C06G126510.1 & 2568 & 855 & $53-540$ & $589-823$ & 6.38 & 97.23 & Chloroplast/Vacuole \\
\hline CITPS5 & Cla97C07G130930.1 & 2571 & 856 & $60-544$ & $593-827$ & 5.66 & 97.47 & Vacuole \\
\hline CITPS6 & Cla97C10G186050.1 & 2595 & 864 & $63-548$ & $597-829$ & 5.81 & 97.54 & Chloroplast/Vacuole \\
\hline CITPS7 & Cla97C11G223240.1 & 2787 & 928 & $94-561$ & $595-816$ & 6.39 & 105.10 & Chloroplast/Vacuole \\
\hline
\end{tabular}

Meanwhile, the seven CITPSs were located in seven different chromosomes (chromosomes 1, 3, 5, 6, 7, 10, and 11) of watermelon (Figure 1A), and a gene duplication event was detected.

Furthermore, a collinear relationship diagram of the dicots watermelon, A. thaliana, and melon TPS family was constructed to further understand the evolutionary mechanism of the watermelon TPS family (Figure 1B). Eight pairs of direct homologous genes were identified between watermelon and A. thaliana, and nine between watermelon and melon. Collinearity analysis detected CITPS3, CITPS4, ClTPS6, and CITPS7 in the three plants, 
suggesting that these genes may be highly conserved. In addition, the $\mathrm{K}_{\mathrm{a}} / \mathrm{K}_{\mathrm{s}}$ ratio of the eight pairs of direct homologous genes between watermelon and $A$. thaliana were less than 0.1 except for CITPS7 / AtTPS2 (supplementary Table S1), indicating purifying selection as the main driving force for the evolution of the watermelon TPS genes.

A

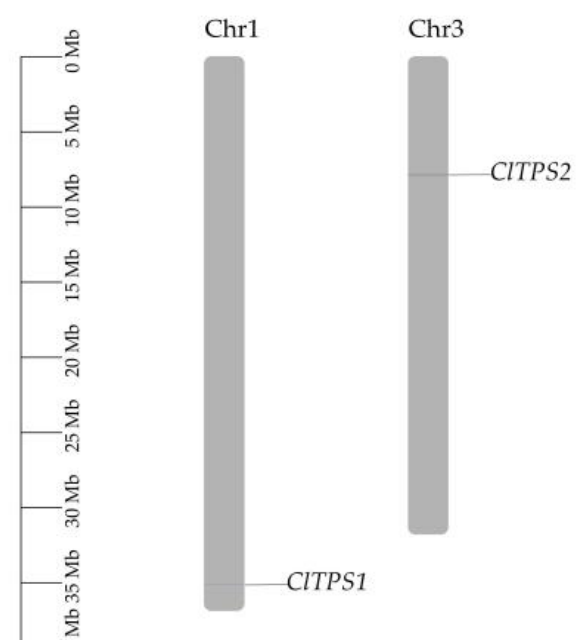

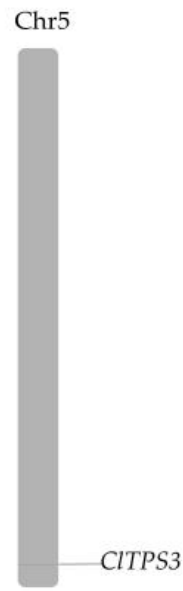

Chr6
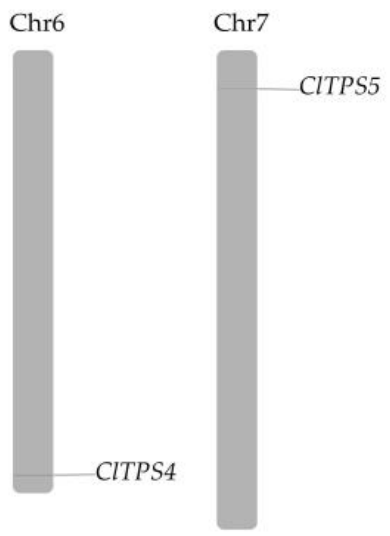

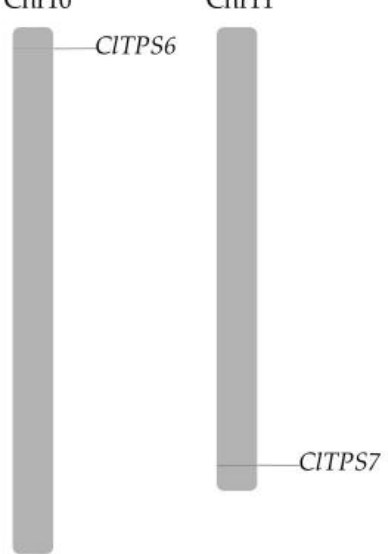

B

Arabidopsis

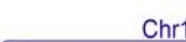

Chr2
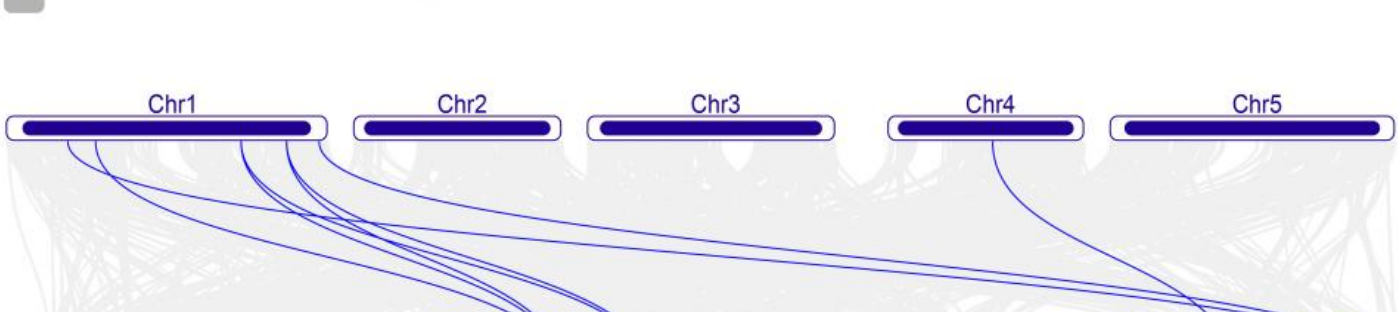

Watermelon

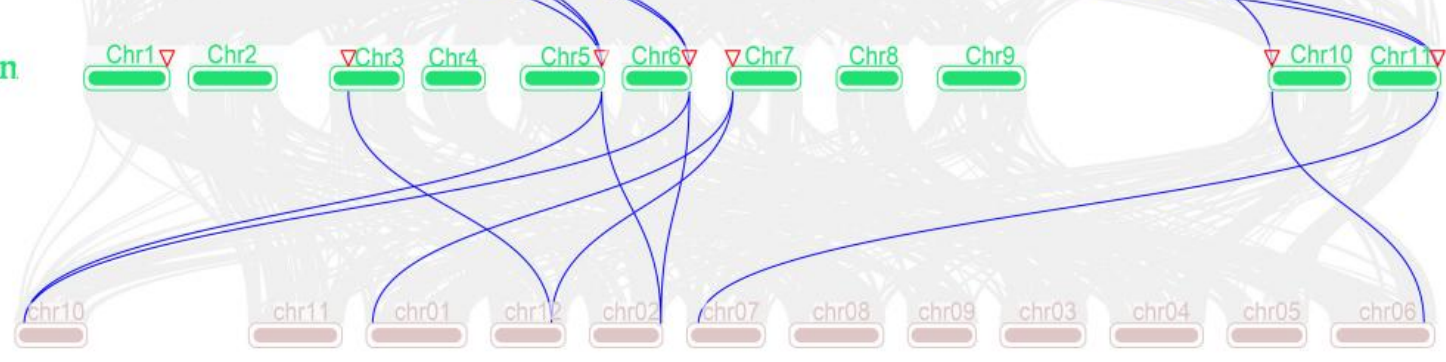

Figure 1. Chromosomal location of CITPS genes and collinearity analysis of A. thaliana, watermelon and melon. (A) Chromosomal location of CITPS genes; (B) collinearity analysis of A. thaliana, watermelon and melon.

\subsection{Phylogenetic Analysis, Structural and Conserved Motifs of ClTPSs}

Seventy TPS proteins sequences from seven species and seven CITPSs were used to construct a phylogenetic tree to understand the evolutionary relationship and classification of CITPSs (Figure 2). All TPS proteins of watermelon were classified into two groups: Class I and Class II. Class I harbored two members, including CITPS2 and CITPS7; Class II harbored five members, including CITPS1, ClTPS3, ClTPS4, CITPS5, and CITPS6. Phylogenetic analysis indicated that the protein was divided into two categories based on their sequences (Figure 3A). Generally, the most closely related members of each group had a similar exonintron structure, with little difference in the length of introns and exons. Analysis of the exon-intron organization showed that all members except ClTPS1 in group II contain 3 exons, while group I members have 17 exons (Figure 3B). 


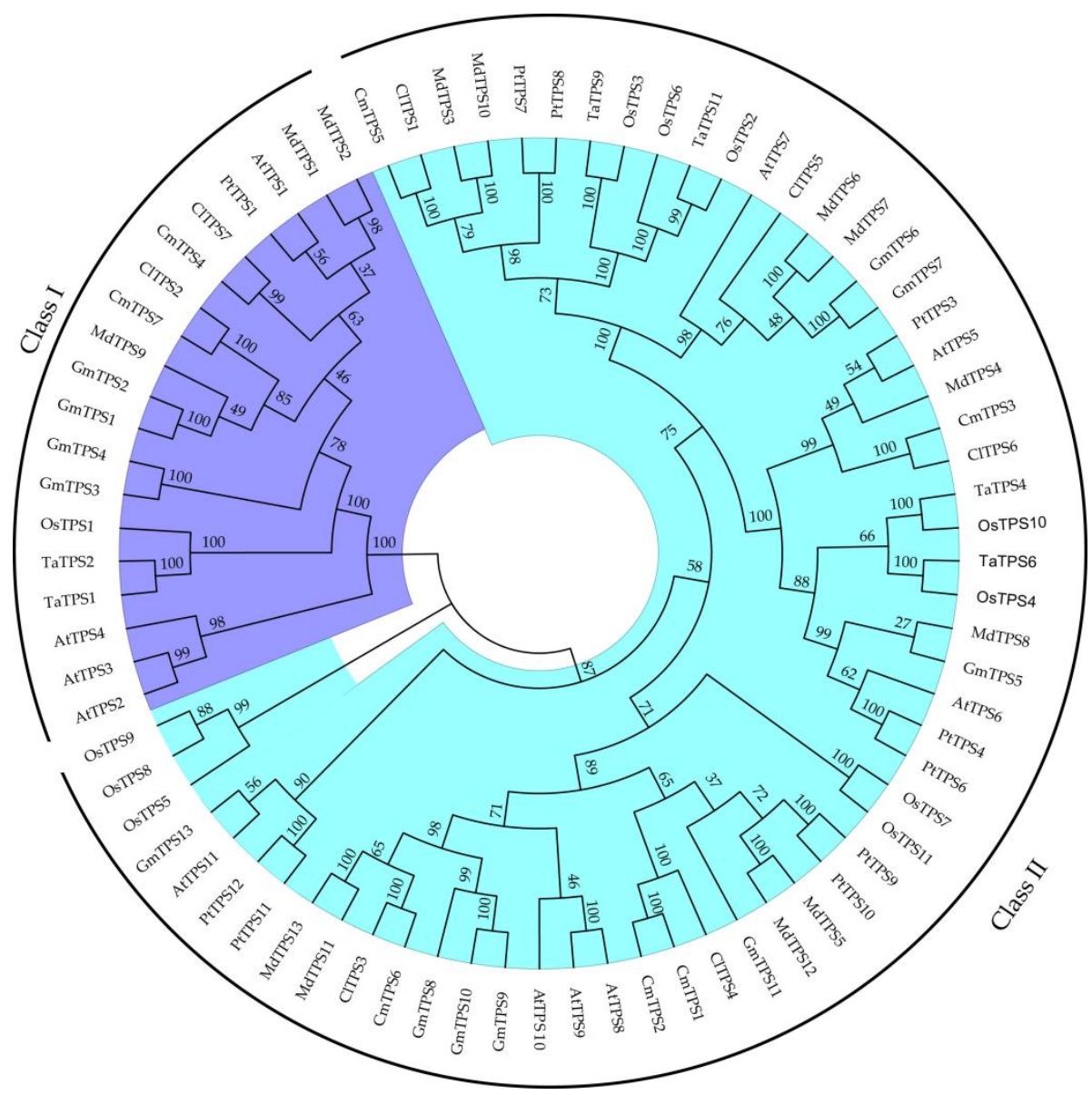

Figure 2. Phylogenetic relationship of TPS proteins among watermelon and other seven species. All TPS proteins were divided into two subgroups, represented by two colors. The green color represents Class I protein, and the blue color represents Class II protein. The phylogenetic tree was constructed by MEGA7 software with 1000 bootstrap replicates, following the neighbor-joining method.

A

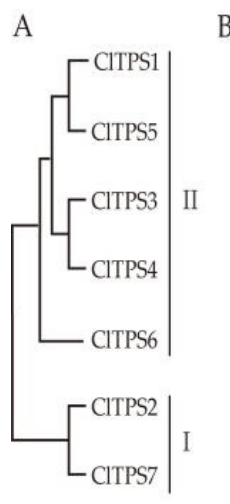

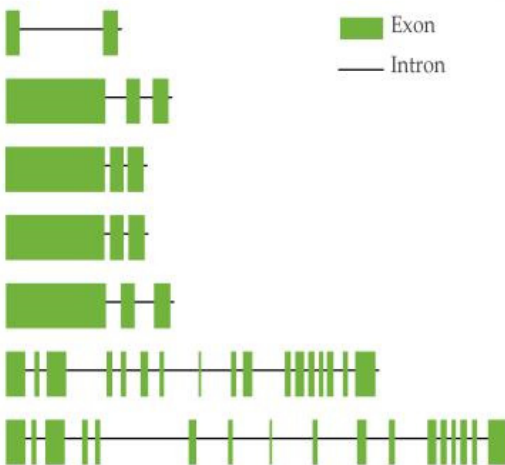

C

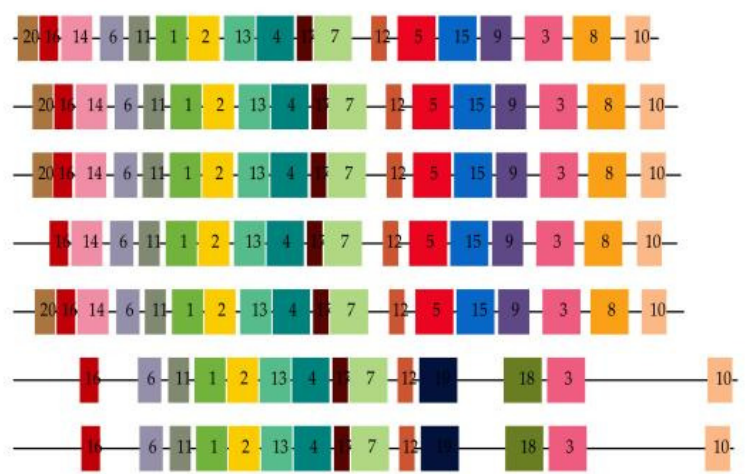

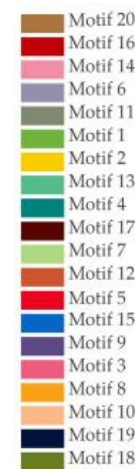

Motif 18

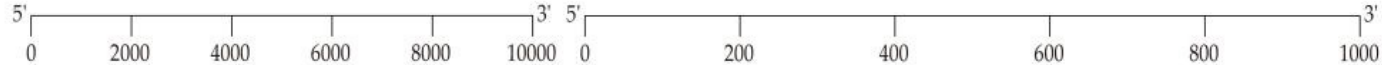

Figure 3. Phylogenetic analysis, gene structure, and conserved motifs of ClTPSs. (A) Phylogenetic analysis of seven CITPSs. (B) Exon/intron organization of CITPSs. (C) Conserved motifs of CITPSs.

Furthermore, MEME software was used to search for motifs and determine the predicted structural characteristics of CITPS proteins (Figure 3C). Interestingly, all the members in group II contained 18 motifs, except CITPS4 lacking motif 20; members of group I had only 14 motifs (lacking 5/8/9/14/15/20 motifs). 


\subsection{Prediction of Cis-Acting Elements of the CITPS Genes}

The $2000 \mathrm{bp}$ sequences upstream of the start site of seven CITPSs were used to identify the potential cis-acting elements in the promoter region for abiotic/biotic stress. The method predicted 249 cis-acting elements in these genes (Figure 4, Table S2). Many cis-acting elements were involved in response to environmental stress, hormone-responsiveness, development, light response, site binding, and other functions (Figure 4A). The most abundant elements were environmental stress-related elements, including those involved in lowtemperature and anaerobic induction; all genes except CTPS7 contained low-temperature responsiveness elements, indicating that they may be considerably affected by the ambient temperature. Meanwhile, ABRE (ABA) was the most abundant among the predicted hormone-responsive elements (Figure $4 \mathrm{~B}$, Table S2).

A

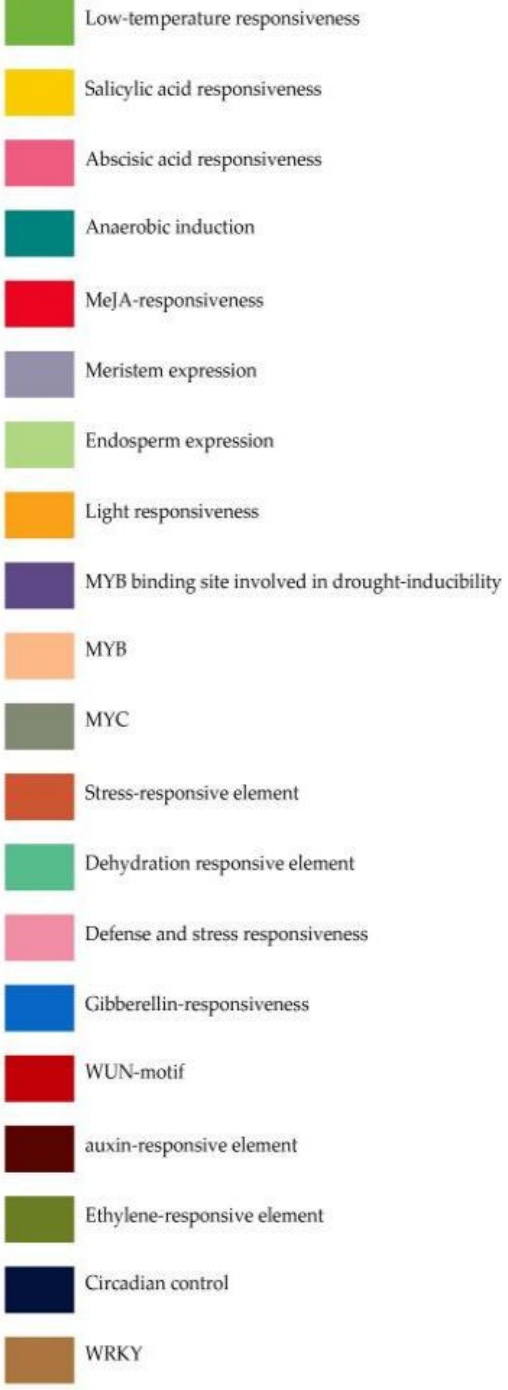

Figure 4. Cis-acting elements of CITPSs. (A) Kind, quantity and position of cis-acting elements in CITPSs; (B) numbers of cis-acting elements.

\subsection{Tissue-Specific Expression of ClTPS Genes}

Initially, the transcript profiles derived from the NCBI database were used to analyze the expression levels of CITPSs in watermelon flowers, fruits, stems, leaves, and roots to elucidate their functions and provide the basis for further understanding of the tissuespecific expression pattern (Figure 5). The seven CITPSs were divided into two groups; the genes clustered in the same group had a similar expression pattern; for example, 
CITPS1/2/7 had low expression levels in fruits and leaves, with no expression of CITPS1 in fruits. The other CITPSs were widely expressed in all tissues, with CITPS5 and CITPS6 showing relatively high expression levels throughout development.
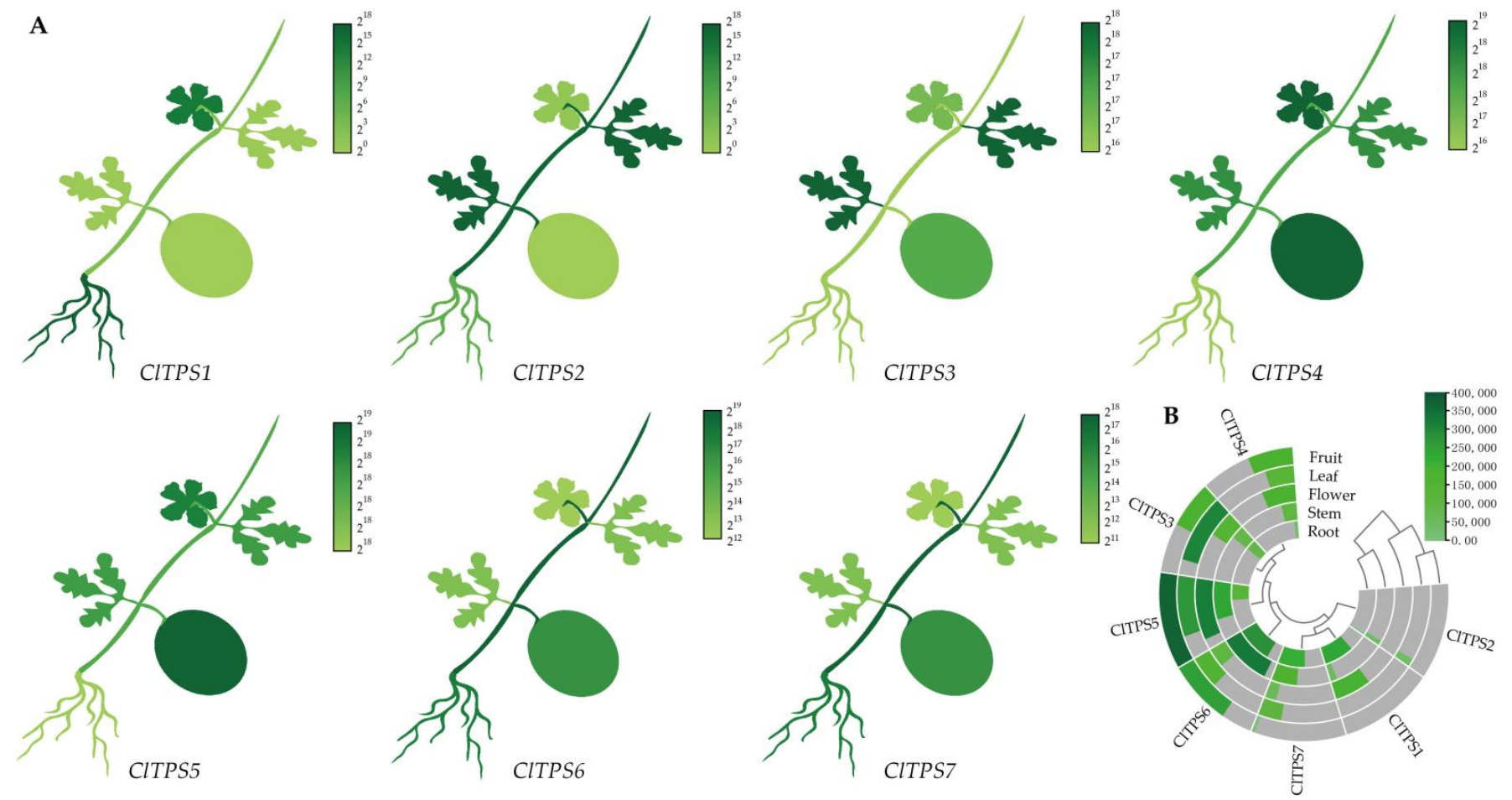

Figure 5. Tissue-specific expression of ClTPSs. (A) The heatmap shown in the form of the whole plant. (B) The heatmap and cluster analysis of tissue-specific expression. The expression levels were derived from NCBI and visualized by TBtools; the dark green represents high expression level, and the light green represents low expression level.

\subsection{Expression of CITPS Genes under Different Salt Stress}

To further explore the role of ClTPSs in salt stress response, the expression levels of ClTPSs under different $\mathrm{NaCl}$ concentrations, including 0, 50, 100, 150, 200, and $250 \mathrm{mM}$, and at various time points, including $0,0.5,6,24,48$, and $72 \mathrm{~h}$, under $200 \mathrm{mM} \mathrm{NaCl}$ were analyzed by qRT-PCR results (Figures 6 and 7). Under different $\mathrm{NaCl}$ concentrations, these genes (CITPS2 had no value) showed similar expression patterns (Figure 6). In the concentration range $0-150 \mathrm{mM}$, the expression levels of the six genes gradually increased and then decreased at 200-250 $\mathrm{mM}$ concentration range.

Further analysis of genes at different time points under $200 \mathrm{mM} \mathrm{NaCl}$ revealed that six genes showed a decrease towards $0.5 \mathrm{~h}$, an increase from 0.5 to $24 \mathrm{~h}$, and then a decrease from 24 to $72 \mathrm{~h}$; the expression level peaked at $24 \mathrm{~h}$ (Figure 7). Dehydration, wilting, and death of watermelon seedlings under high osmotic conditions probably resulted in this expression pattern. Meanwhile, CITPS3 showed the highest expression level among all treatments, suggesting it is a key gene involved in salt stress response.

\subsection{Functional Analysis of ClTPS3 Gene}

The above results proved that salt stress significantly induced CITPS3. A genetic transformation experiment was carried out in A. thaliana, and the plants were grown under $200 \mathrm{mM} \mathrm{NaCl}$ stress to verify the function of CITPS3 further. The results showed that the expression level of CITPS3 in transgenic plants OE1, OE2, and OE3 was significantly higher than that of the wild-type plants (CK), which was 7.4, 7.8 and 8.2 times higher than $\mathrm{CK}$, respectively (Figure 1). 

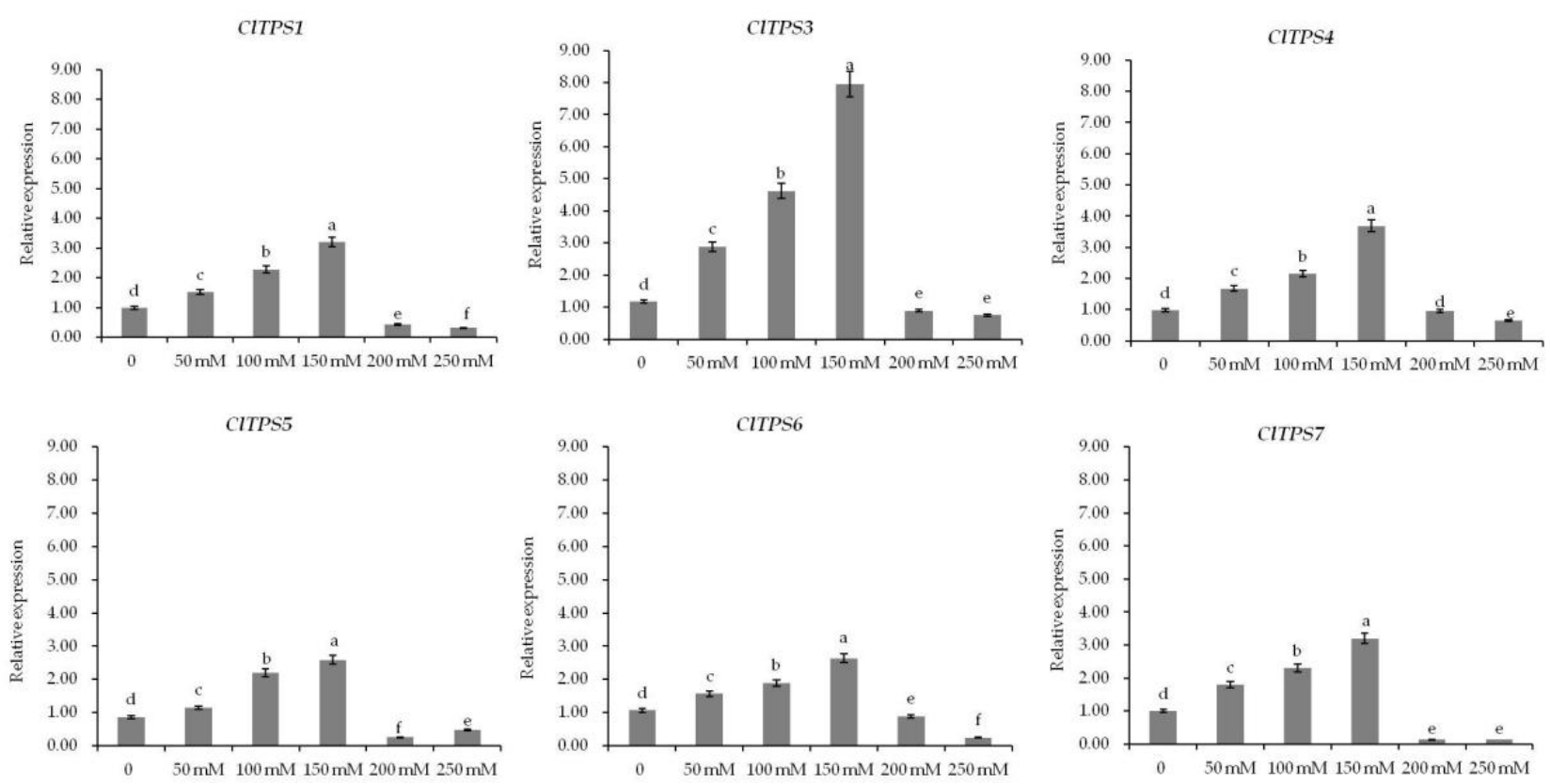

Figure 6. Expression analysis of CITPSs under different $\mathrm{NaCl}$ concentrations. ClTPS2 expression was not detected. Error bars indicate the SD of three biological replicates. Different letters indicate significant differences within treatments by ANOVA $(p<0.05)$.
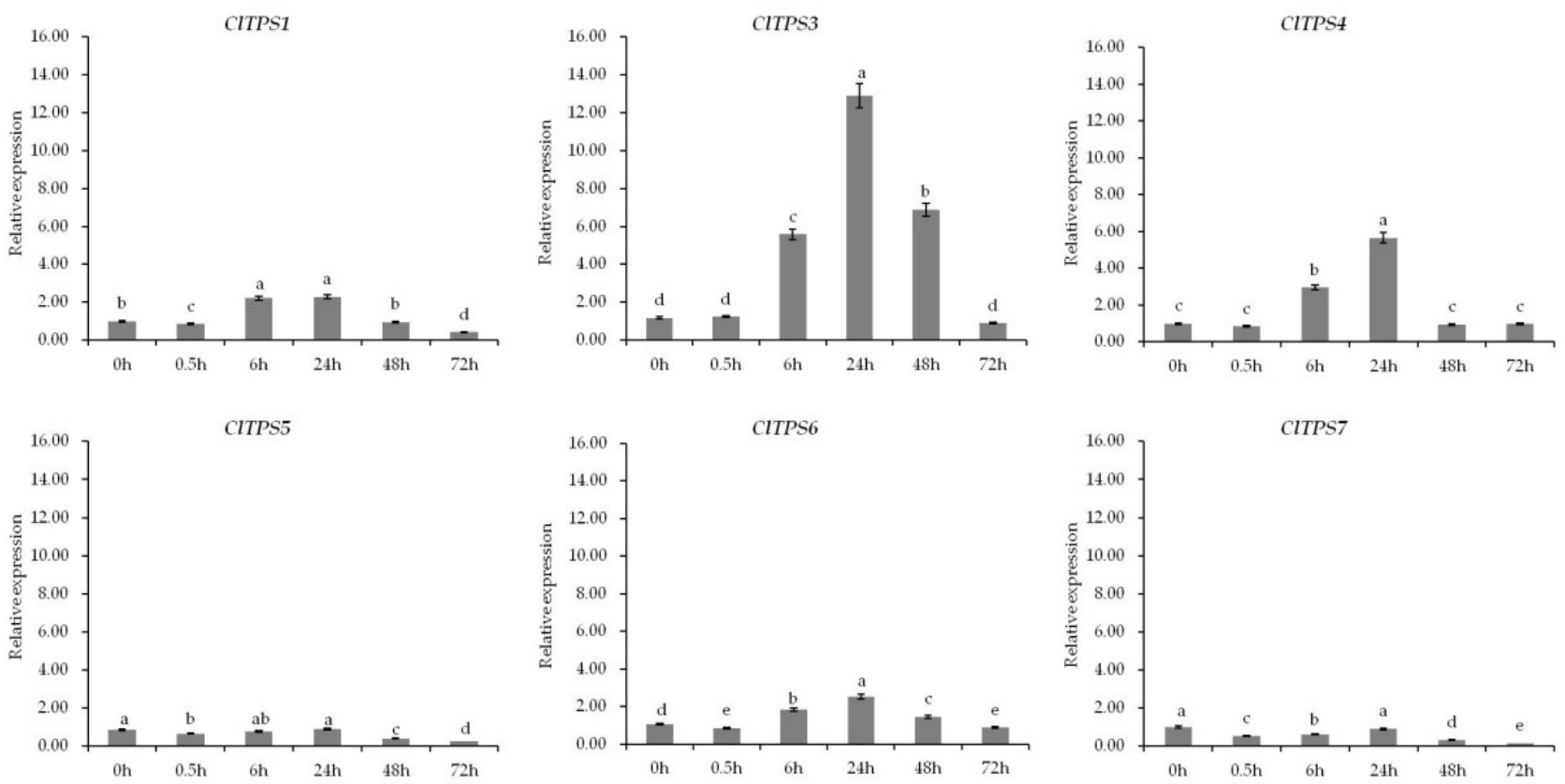

Figure 7. Expression analysis of ClTPSs at different time points under $200 \mathrm{mM} \mathrm{NaCl}$ stress. ClTPS2 expression was not detected. Error bars indicate the SD of three biological replicates. Different letters indicated significant differences within treatments by ANOVA $(p<0.05)$.

The transgenic plants grew normally under high salt concentration, while the growth of CK was significantly inhibited (Figure 8B). The transgenic plants had a root length of $35.19,36.92$, and $39.03 \mathrm{~mm}$, respectively, which was three times more than that of CK (Figure $8 \mathrm{C}$ ). To investigate the salt tolerance of transgenic plants and CK, the seedlings were treated with $200 \mathrm{mM} \mathrm{NaCl}$ for one week, and the results showed that transgenic plants had less wilting and a higher survival rate than CK (Figure 8C). To confirm this result, trehalose content, fresh weight $(\mathrm{FW})$, dry weight $(\mathrm{DW})$, and relative water content 
(RWC) were measured. The results showed that the trehalose content of transgenic plants was significantly higher than that of CK (Figure 8E), and the data of FW, DW and RWC exhibited similar trends (Figure $8 \mathrm{~F}-\mathrm{H}$ ). In addition, the MDA content of the CK was significantly higher than that of transgenic plants, while POD activity and SOD activity were significantly lower than that of transgenic plants (Figure 8I-K), which indicates that ClTPS3-overexpressed reduced the content of $\mathrm{H}_{2} \mathrm{O}_{2}$ and $\mathrm{O}_{2}-$ and reduced the cell membrane damage. These results suggest that the CITPS3 gene may improve salt tolerance.

A
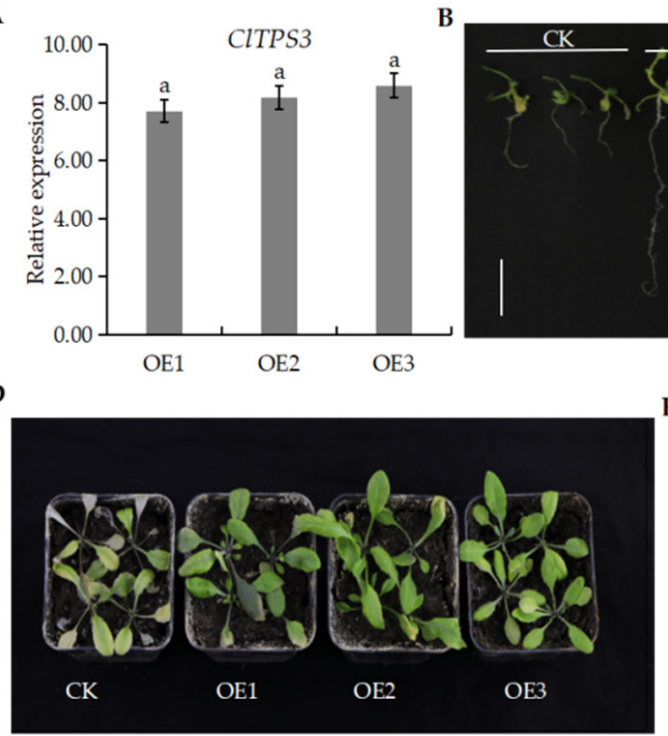
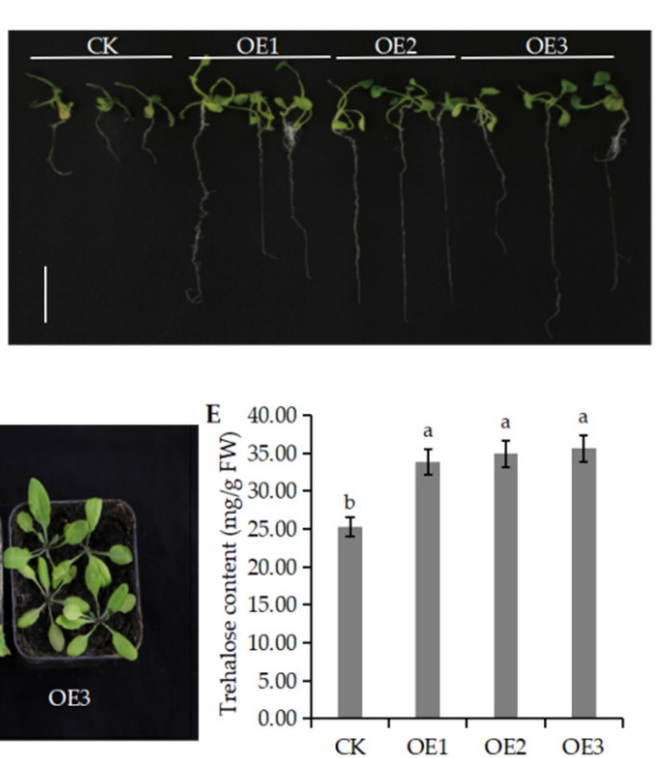
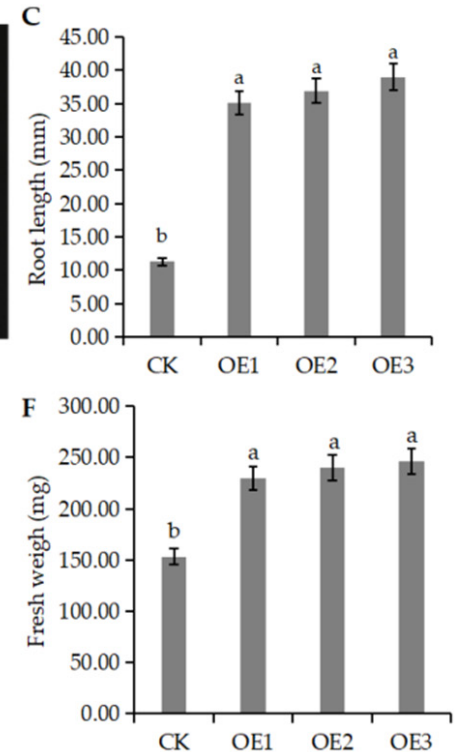
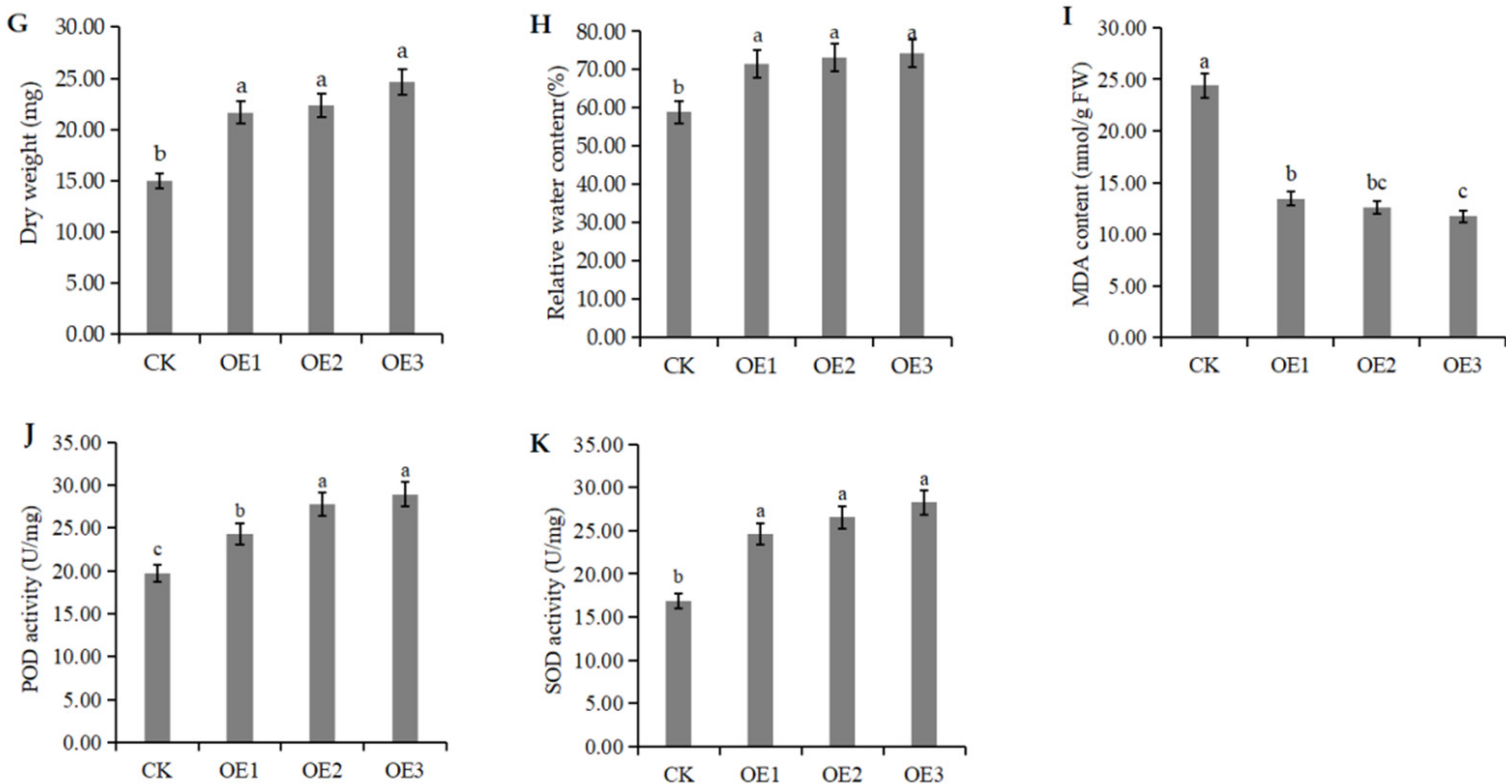

Figure 8. Phenotypic analysis of CITPS3 overexpressed A.thaliana plants. (A) The expression level of CITPS3 in different A.thaliana lines. (B) The growth status of wild type and transgenic seedlings under $200 \mathrm{mM} \mathrm{NaCl}$ stress, the white scale range represents $1 \mathrm{~cm}$. (C) The root length of different A.thaliana lines under $200 \mathrm{mM} \mathrm{NaCl}$ stress. (D) The growth status of different A.thaliana lines adult plant under $200 \mathrm{mM} \mathrm{NaCl}$ stress. (E) Trehalose content of different A.thaliana lines. (F) Fresh weight, (G) dry weight, (H) relative water content, (I) MDA content, (J) POD activity and (K) SOD activity of different A.thaliana lines under $200 \mathrm{mM} \mathrm{NaCl}$ stress. CK represents wild-type A. thaliana plants, and $\mathrm{OE} 1, \mathrm{OE} 2$, and OE3 are transgenic A. thaliana plants. Error bars indicate the SD of three biological replicates. Different letters indicate significant differences within treatments by ANOVA $(p<0.05)$. 


\subsection{Functional Protein Association Networks of ClTPS Genes}

As mentioned above (Figure 4), many MYB and bHLH transcription factor binding sites were detected in the promoter region of CITPS genes, indicating their regulation by the transcription factors. A functional protein association network analysis was performed to screen for transcription factors that regulate CITPS genes. Studies have reported the roles of MYB and bHLH transcription factor family genes in regulating watermelon response to abiotic stress $[45,46]$. Therefore, the interactions among the TPS proteins, MYB, and bHLH transcription factors were predicted using the STRING program. The analysis indicated a direct regulatory relationship between TPS9 (ClTPS3) and bHLH093 (ClbHLH93), while MYB36 (ClMYB9), MYB78 (ClMYB69), and MYB79 (ClMYB51) appeared to regulate bHLH093 (Figure 9).

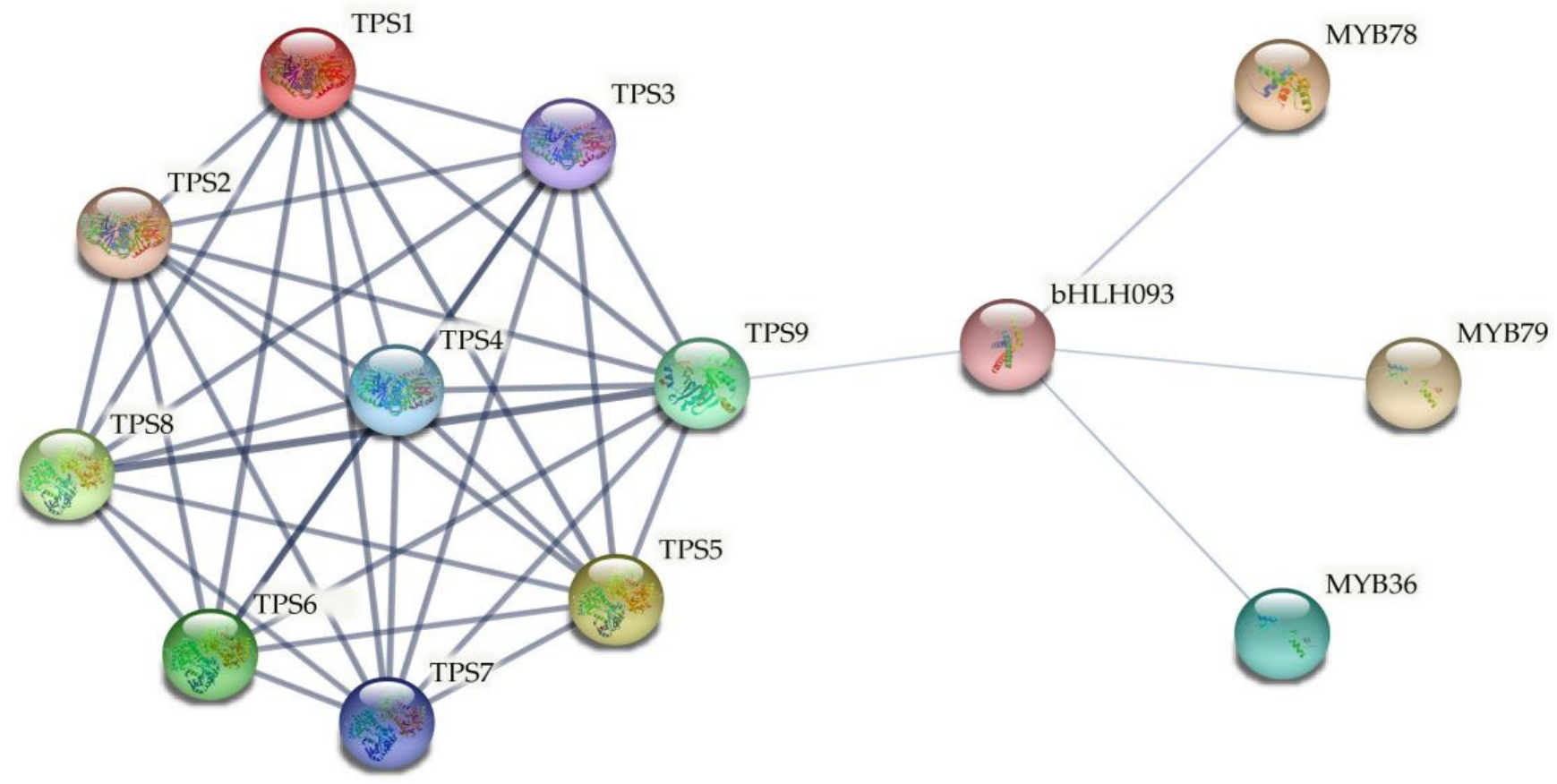

Figure 9. Functional protein association networks using the TAIR accessions of MYB36 (At5g57620.1, ClMYB9, Cla97C01G017110.1); MYB78 (At5g49620.2, ClMYB69, Cla97C09G167270.1); MYB79 (At4g13480.1, ClMYB51, Cla97C05G084530.1); bHLH093 (At5g65640.1, ClbHLH93, Cla97C11G220830.1); AtTPS1 (At1g78580.1, ClTPS1, Cla97C11G223240.1); AtTPS2 (At1g16980.1, ClTPS7, Cla97C11G223240.1); AtTPS3 (At1g17000.1, ClTPS7, Cla97C11G223240.1); AtTPS4 (At4g27550.1, ClTPS7, Cla97C11G223240.1); AtTPS5 (At4g17770.1, ClTPS6, Cla97C10G186050.1); AtTPS6 (At1g68020.1, ClTPS6, Cla97C10G186050.1); AtTPS7 (At1g06410.1, ClTPS5, Cla97C07G130930.1); AtTPS8 (At1g70290.1, ClTPS3, Cla97C05G107320.1); AtTPS9 (At1g23870.1, ClTPS3, Cla97C05G107320.1). Blue lines represent gene interaction confidence (0 to 1); thick lines indicate confidence score higher than 0.85 , while thin lines indicate confidence score between 0.26 and 0.84 .

\section{Discussion}

The present study adopted a bioinformatic approach to identify and characterize the watermelon TPS gene family. Seven CITPS genes were identified in watermelon, which was less than the number of genes in A. thaliana and rice (11 TPS gene members). Previous studies revealed that fragment duplication resulted in three TPS genes in rice, genomewide duplication produced one TPS gene in A. thaliana; AtTPS2 and AtTPS3 genes were produced by fragment duplication from AtTPS1 [44]. However, in this study, no tandem duplication or fragment duplication event was detected in the CITPS gene family, indicating different ancestor genes for these seven CITPSs. This observation confirmed the presence of at least seven TPS genes in the common ancestor of monocotyledonous and dicotyledonous 
plants [47]. Meanwhile, in genetics, the $\mathrm{K}_{\mathrm{a}} / \mathrm{K}_{\mathrm{s}}$ ratio is used as an indicator of selective pressure (the force applied by natural selection) acting on a protein-coding gene. $\mathrm{K}_{\mathrm{a}} / \mathrm{K}_{\mathrm{s}}$ greater than 1 indicates a strong positive selection, genes with $\mathrm{K}_{\mathrm{a}} / \mathrm{K}_{\mathrm{s}}$ between 0.5 and 1 have a weak positive selection, and those with $\mathrm{K}_{\mathrm{a}} / \mathrm{K}_{\mathrm{s}}$ less than 1 are negatively selected (purifying selection) [48-50]. In this study, the analysis of evolutionary selective pressure indicated that the CITPS genes were subjected to a purifying selection, which may partly explain fewer genes than A. thaliana.

According to the gene structure and enzyme activity, TPS family genes in plants are classified into two classes: Class I and Class II [51-55]. In the phylogenetic tree, ClTPS2 and CITPS7 clustered with AtTPS1, AtTPS2, AtTPS3, AtTPS4, and OsTPS1, belonging to the Class I TPS subfamily, while the other five CITPS genes belonged to the Class II TPS subfamily. Studies have also shown that the Class I genes have TPS activity, while the function of Class II TPS subfamily genes is not clear [52,56-58]. However, few researchers pointed out that the N-terminal of some genes in Class II TPS subfamily have the TPS domain of the conserved sites of glycotransferase and the TPP domain of the conserved sites of two phosphohydrolases at the C-terminal; the presence of these two domains indicate that the gene members are either bifunctional or act as a TPS complex subunit $[54,55,59]$. Long et al. [28] predicted ten glycosylation sites and forty-nine phosphorylation sites for the protein encoded by the CITPS1 gene, indicating TPS and TPP activities for the ClTPS1 gene. The functional verification of the TPS gene family in maize revealed both TPS activity and TPP activity for the ZmTPS3 gene of the Class II subfamily [60]. These observations collectively indicate that the TPS genes may quickly respond to stress and synthesize trehalose to help watermelon survive under stress.

The CITPS genes of Class I and Class II subfamily had significantly different numbers of exons, indicating evolutionary differences between them similar to Populus, A. thatiana, and rice [44]. Studies have proven a close relationship between the structure and function of genes [61]. Similarly, the differences in the expression patterns and functions of Class I and Class II CITPS genes may be related to the wide differences in the exon-intron structure. In this study, two Class I members and four Class II members showed similar tissue expression patterns (Figure 5B), probably because few introns are required during the selective splicing of mRNA to subsequently regulate the structure and function of the protein encoded by the gene. Meanwhile, some genes may have enhanced mRNA transcription and transport, leading to different tissue-specific patterns and different expression levels $[62,63]$.

TPS is a gene that encodes a key enzyme in the trehalose pathway. The promoter region of CITPS genes contains a variety of signal response elements, which can respond to various stress conditions. Moreover, each CITPS gene contains different stress response elements, indicating that different signals may induce each gene. The CITPS5 gene has the largest number of hormone-responsive cis-acting elements, consistent with the highest expression level in the tissues. Many cis-acting elements involved in drought-inducibility and anaerobic induction were identified in the CITPS3 gene, in agreement with the high expression level under osmotic stress. Studies have demonstrated that an important feature of drought and salt stress is cell osmosis, which leads to ABA accumulation as an adaptive response [64]. Meanwhile, the relationship between ScTPS and ABA signals in sugarcane indicated the role of ScTPS in drought tolerance [65]. Most of the ClTPS genes also had ABA cis-acting elements, suggesting their roles in the drought stress response.

Studies have shown that high temperature, high salt concentration, and drought stress significantly increased the expression levels of TPS1 and TPS7 genes in potatoes, suggesting the role of the TPS gene in the signal transduction pathway of stress tolerance [13]. Similarly, the expression level of PhTPS6 in petunia was significantly upregulated after $12 \mathrm{~h}$ of low-temperature treatment, with a gradual increase in the expression level with the treatment time [66]. PhTPS6 showed the same expression pattern after $\mathrm{NaCl}$ treatment, suggesting its role under low temperature and salt stress [66]. A recent study in sugarcane showed that salt and drought induced the expression of the ScTPS1 gene, which indicated that sugarcane maintained the cell osmotic stability by increasing trehalose-6-phosphate 
production and alleviated the simulated stress. These observations suggested that genetic engineering of endogenous ScTPS1 gene involved in trehalose biosynthesis may improve the drought tolerance of sugarcane [13]. Similarly, salt stress markedly induced CITPS3 (Figures 6 and 7). Previous studies had proved that trehalose could improve the salt tolerance of plants by increasing the activity of antioxidant enzymes, and it was found that the activities of SOD, CAT, POD were positively correlated with the salt tolerance of plants [29,67]. In addition, trehalose significantly reduced the accumulation of MDA in tomato, indicating that trehalose can reduce the degree of cell membrane damage and improve the salt tolerance of tomato [68]. In this study, the trehalose content of ClTPS3 transgenic A.thaliana plants was significantly increased, and the activities of SOD and POD were also significantly increased. In addition, the MDA content was significantly decreased, while the relative water content was significantly increased, indicating that CITPS3 played an important role in the salt tolerance of watermelon. Furthermore, the results of STRING functional protein association networks showed that ClMYB and ClbHLH transcription factors most likely regulated only CITPS3 among the seven CITPS genes. These results indicate a putative role of ClTPS3 in watermelon response to various abiotic stresses. Therefore, effective use of the CITPS3 gene may help watermelon maintain growth and production under salt stress.

\section{Materials and Methods}

\subsection{Identification and Characterization Analysis of Putative Watermelon TPS Genes}

In this study, 11 AtTPS protein sequences and 11 OsTPS protein sequences [44] were used to blast against the CuGenDB (http:/ / cucurbitgenomics.org/organism/21) (accessed on 20 Octomber 2021) [69] to identify TPS genes of watermelon. The Conserved Domains database (https:/ / www.ncbi.nlm.nih.gov/Structure/cdd/wrpsb.cgi) (accessed on 8 June 2021) was used to ensure that all candidate TPSs contained the TPS domain. In addition, the online software ExPASy Proteomics Server (http:/ / web.expasy.org/protparam/) (accessed on 8 June 2021) was used to analyze the molecular weight, length, and isoelectric point of the watermelon TPS proteins [70], and the online software Cell-PLoc (http:/ / www.csbio.sjtu.edu.cn/bioinf/Cell-PLoc-2/) (accessed on 8 June 2021) was used to predict their subcellular localization [71].

\subsection{Chromosomal Localization, Phylogenetic Analysis, Duplication Events, and Collinearity Analysis of CITPS Genes}

The chromosomal distribution of CITPSs was derived from CuGenDB. The TBtools software [72] was used to determine the chromosome localization and the CITPSs duplication events. Furthermore, 77 protein sequences of various species, including watermelon, Populous, Cucumis melo, Malus domestica, A. thaliana, Oryza sativa, Glycine max, and Triticum aestivum, were used to construct the phylogenetic tree. Amino acid sequence alignment was carried out using Clustal W [73], and then the phylogenetic trees were constructed following the neighbor-joining (NJ) method with 1000 bootstrap using the MEGA 7.0 software [74]. TPS genes duplication events, collinearity, and selective evolutionary pressure were analyzed using the TBtools software [72].

\subsection{Analysis of ClTPS Gene Structures and Conserved Motifs}

The structure (exon-intron arrangement) of CITPS genes was obtained from CuGenDB and visualized using TBtools. Then, the putative conserved motifs of CITPS protein sequences were analyzed using the MEME program (http:/ / meme-suite.org/tools/meme) (accessed on 8 June 2021), with any number of repetitions, a maximum of 20 motifs; and an optimum width of each motif between 6 and 60 residues [75]; the conserved domains were visualized using TBtools. 


\subsection{Analysis of Cis-Acting Elements}

TBtools was used to extract the $2000 \mathrm{bp}$ sequences upstream of the transcriptional start site (ATG) of the CITPS genes as the putative promoter region; these sequences were submitted to Plantcare (http:/ / bioinformatics.psb.ugent.be/webtools/plantcare/html/) (accessed on 8 June 2021) to identify the cis-acting elements in the promoter region.

\subsection{Tissue-Specific Expression Patterns and Expression Levels under Different Stresses of CITPS Genes}

The data of different tissues, including flower (GSE69073), fruit (PRJNA338036), stem (SRP012853), leaf (PRJNA381300), and root (PRJNA641525), and under different stresses, such as drought (GSE144814), osmotic stress (PRJNA381300), heat shock (PRJNA504354) and cold (PRJNA328189), were retrieved from the NCBI database (https:/ / www.ncbi.nlm.nih.gov/) (accessed on 22 June 2021). The data were first downloaded from the SRA database, converted into fastq format, and uploaded into the Kallisto Super Wrapper of TBtools to obtain the transcript expression matrix. Finally, the gene expression matrix was obtained from the transcript expression matrix using the Trans Value Sum of TBtools. Furthermore, hierarchical clustering and heatmap of CITPS genes were generated using TBtools.

\subsection{Plant Growth and Treatments}

Watermelon ("HQ-2" variety) seedlings were maintained in Hoagland solution in a growth chamber at $25^{\circ} \mathrm{C}$ under a photoperiod of $16 \mathrm{~h}$ light $/ 8 \mathrm{~h}$ dark. After growing for 30 days, the seedlings were grown hydroponically in Hoagland solution containing 0 (control), 50, 100, 150, 200, or $250 \mathrm{mM} \mathrm{NaCl}$; thirty seedlings were maintained per treatment. Control plants (were cultured in standard Hoagland solution) were cultured in parallel. Seedlings were sampled after 3 days of salt treatment. In addition, samples under $200 \mathrm{mM}$ $\mathrm{NaCl}$ were collected at $0,0.5,6,24,48$, and $72 \mathrm{~h}$. Finally, all the samples were immediately frozen in liquid nitrogen and stored at $-80{ }^{\circ} \mathrm{C}$ until for RNA extraction. Three seedlings were mixed into one sample, and three biological replicates were maintained per treatment.

\subsection{RNA Extraction and Quantitative Real-Time-PCR}

Total RNA was isolated using the Plant RNA Kit (Huayueyang, Beijing, China) according to the manufacturer's protocol. The first strand of cDNA was obtained using a PrimeScript RT reagent Kit (TaKaRa, Dalian, China). qRT-PCR was performed on the Light Cycler480 Real-Time System (Bio-Rad Laboratories) with the method described previously [61]. ClActin was used as the reference gene, and the specific primers are shown in Supplementary Table S3. The data were analyzed using the $2^{-\Delta \Delta \mathrm{Ct}}$ method [76].

\subsection{Functional Analysis of ClTPS3 Gene}

The coding sequence of ClTPS3 (Cla97C05G107320.1) was inserted into the plant transformation vector pRI101-AN at Nde I-Kpn I sites to generate the ClTPS3-overexpressing recombinant vector, and the specific primer sequences used for PCR amplification were as follows: 5'-CATATGATGGCATCAAGATCCCCCAC-3' ${ }^{\prime}$ and $5^{\prime}$-GGTACCTCAAAAAACACTC TCAAAAGAAACAC-3'. The construct was transformed into Agrobacterium tumefaciens strain GV3101.

The Agrobacterium dipping flower method was employed to infect $A$. thaliana [77]. The seeds of the overexpressed homozygote and the wild-type $A$. thaliana were disinfected and seeded on the MS medium and cultured under normal light. The overexpressed $(O E)$ and wild-type A.thaliana (CK) plants were transferred to an MS medium containing $200 \mathrm{mM}$ $\mathrm{NaCl}$ for stress treatment. After 7 days, the root length was measured using a vernier caliper (SHRN 0-300 mm, Guilin, China), and at least ten seedlings were measured for each line. In addition, the 3-week-old $O E$ and CK seedlings were treated with $200 \mathrm{mM} \mathrm{NaCl}$ for 7 days, then three seedlings were sampled for the fresh weight (FW), dry weight (DW) and relative water content (RWC) measurement, and ten seedlings were immediately frozen in liquid nitrogen and stored at $-80^{\circ} \mathrm{C}$ until for RNA extraction and indexes analysis. 
Furthermore, the trehalose, MDA, POD, and SOD content were determined using BC0330 (Solarbio, Beijing, China), KTB1050, KTB1150, and KTB1030 (Abbkine, Beijing, China) kits, respectively. The absorbance was measured using the SpectraMax i3X Multimode Detection Platform Molecular Devices (Molecular Devices, China).

All data were statistically analyzed using three biological replicates and expressed as mean values \pm standard deviation (SD). SPSS 18.0 statistical software was used for variance analysis, and differences were considered statistically significant at a $p$-value of $0.05(p<0.05)$.

\title{
4.9. Functional Protein Association Networks of ClTPS Genes
}

A TPS-related functional protein association network was built using the online software STRING (http:/ /stringdb.org) (accessed on 1 May 2021) using the TAIR gene ID of genes related to TPS. The amino acid sequences of the MYB transcription factors and bHLH transcription factors were derived from the articles of Wang [45] and He [46]. The gene ID of $A$. thaliana may be responsible for multiple members in watermelon. The transcription factors with the highest amino acid identity were selected (Table S4). The confidence level of minimum required interaction score parameters was set at 0.25 .

\section{Conclusions}

In this study, a total of seven TPS genes were identified through genome-wide analysis in watermelon, divided into two groups, and located on seven chromosomes. Tissuespecific expression and stress response analysis showed diversity and specificity in the expression patterns of ClTPSs in different tissues and under various stresses. The ClTPS3 gene was highly expressed under salt stress, suggesting an essential role in watermelon's response to salt stress. Our results will help to lay a foundation for further understanding the structures and characteristics of the TPS gene family and improving the efficiency of watermelon breeding.

Supplementary Materials: The following are available online at https:/ /www.mdpi.com/article/ 10.3390/ijms23010276/s1.

Author Contributions: Conceptualization, G.Y., Y.Z. and D.S.; methodology, G.Y.; software, G.Y. and Y.Z.; validation, G.Y.; formal analysis, G.Y.; investigation, G.A. and W.L; resources, G.A., W.L. and W.S.; data curation, G.Y.; writing — original draft preparation, G.Y.; writing—review and editing, Y.Z. and D.S.; visualization, G.Y.; supervision, Y.Z., J.L. and D.S.; project administration, G.Y., Y.Z., J.L. and D.S.; funding acquisition, G.Y., Y.Z., J.L. and D.S. All authors have read and agreed to the published version of the manuscript.

Funding: This research was funded by grants from the China Agriculture Research System of MOF and MARA (CARS-25); Central Public-interest Scientific Institution Basal Research Fund (1610192021308); Province Key Scientific and Technological Project in Henan (202102110194, 212102110424); Special Scientific Research Service Fee of the Chinese Academy of Agricultural Sciences (Y2019XK16-03); the Agricultural Science and Technology Innovation Program (CAAS-ASTIP-2021-ZFRI); screening and technical demonstration and popularization of fruit and melon varieties in Xinjiang (Y2021XK14); special funds for basic research and special basic research (20131415).

Institutional Review Board Statement: Not applicable.

Informed Consent Statement: Not applicable.

Data Availability Statement: Not applicable.

Conflicts of Interest: The authors declare no conflict of interest.

\author{
Abbreviations \\ T6P trehalose-6-phosphate \\ UDPG uridine diphosphate glucose \\ TPS trehalose-6-phosphate synthetase \\ TPP trehalose-6-phosphate phosphatase
}




$\begin{array}{ll}\text { TRE } & \text { trehalase } \\ \text { SOD } & \text { superoxide dismutase } \\ \text { APX } & \text { ascorbic acid peroxidase } \\ \text { POD } & \text { peroxidase } \\ \text { CAT } & \text { catalase } \\ \text { MDA } & \text { malondialdehyde } \\ \text { O2- } & \text { superoxide anion } \\ \text { PRO } & \text { proline } \\ \text { ROS } & \text { reactive oxygen species } \\ \text { ORF } & \text { open reading frame } \\ \text { pI } & \text { isoelectronic point } \\ \text { MWs } & \text { molecular weights } \\ \text { NJ } & \text { neighbor-joining } \\ \text { FW } & \text { fresh weight } \\ \text { DW } & \text { dry weight } \\ \text { RWC } & \text { relative water content }\end{array}$

\section{References}

1. Elbein, A.D. New insights on trehalose: A multifunctional molecule. Glycobiology 2003, 13, 17-27. [CrossRef]

2. Feofilova, E.P.; Usov, A.I.; Mysyakina, I.S.; Kochkina, G.A. Trehalose: Chemical structure, biological functions, and practical application. Microbiology 2014, 83, 184-194. [CrossRef]

3. Wang, Y.W.; Quan, S.J.; Ma, H.; Liu, D.H.; Xie, F.H. Review on the mechanism of trehalose protecting plant tissues and animal cells. Jiangsu Agric. Sci. 2019, 47, 14-18.

4. Park, M.; Mitchell, W.J.; Rafii, F. Effect of trehalose and trehalose transport on the tolerance of Clostridium perfringens to environmental stress in a wild type strain and its fluoroquinolone-resistant mutant. Int. J. Microbiol. 2016, $48,29716$.

5. Tian, T.; Gang, Z.; Dan, H.; Zhu, K.; Chen, D.; Zhang, Z.; Wei, Z.; Cao, Y.; Zhou, P. Effects of vitrification cryopreservation on follicular morphology and stress relaxation behaviors of human ovarian tissues: Sucrose versus trehalose as the non-permeable protective agent. Hum. Reprod. 2015, 30, 877-883. [CrossRef]

6. Schluepmann, H.; Dijken, A.V.; Aghdasi, M.; Wobbes, B.; Smeekens, P.S. Trehalose Mediated Growth Inhibition of Arabidopsis Seedlings Is Due to Trehalose-6-Phosphate Accumulation. Plant Physiol. 2004, 135, 879-890. [CrossRef]

7. O'Hara, L.E.; Paul, M.J.; Wingler, A. How Do Sugars Regulate Plant Growth and Development? New Insight into the Role of Trehalose-6-Phosphate. Mol. Plant 2013, 6, 261-274. [CrossRef]

8. Fernandez, O.; Vandesteene, L.; Feil, R.; Baillieul, F.; Lunn, J.E.; Clément, C. Trehalose metabolism is activated upon chilling in grapevine and might participate in Burkholderia phytofirmans induced chilling tolerance. Planta 2012, 236, 355-369. [CrossRef]

9. Zhang, W.; Wang, Y.F.; Guo, Y.P. Review on crosstalk regulation involving in trehalose-6-phosphate signal in plant. Plant Physiol. J. 2016, 52, 394-400.

10. Paul, M. Trehalose 6-phosphate. Curr. Opin. Plant Biol. 2007, 10, 303-309. [CrossRef]

11. Eastmond, P.J.; Graham, I.A. Trehalose metabolism: A regulatory role for trehalose-6-phosphate? Curr. Opin. Plant Biol. 2003, 6, 231-235. [CrossRef]

12. Dan, Y.; Niu, Y.; Wang, C.; Yan, M.; Liao, W. Genome-wide identification and expression analysis of the trehalose-6-phosphate synthase (TPS) gene family in cucumber (Cucumis sativus L.). PeerJ 2021, 9, e11398. [CrossRef]

13. Xu, Y.C.; Wang, Y.J.; Mattson, N.; Yang, L.; Jin, Q. Genome-wide analysis of the Solanum tuberosum (potato) trehalose-6-phosphate synthase (TPS) gene family: Evolution and differential expression during development and stress. BMC Genom. 2017, 18, 926. [CrossRef]

14. Garg, A.; Owens, T.; Setter, T.; Miller, W.; Kim, J.K.; Kochian, L.; Wu, R. Trehalose Accumulation in Rice, Maize, and Wheat Plants Confers High Tolerance Levels to Different Abiotic Stresses. In Vitro Cell Dev. 2010, 46, S204.

15. Miranda, J.A.; Avonce, N.; Suárez, R.; Thevelein, J.M.; Dijck, P.V.; Iturriaga, G. A bifunctional TPS-TPP enzyme from yeast confers tolerance to multiple and extreme abiotic-stress conditions in transgenic Arabidopsis. Planta 2007, 226, 1411-1421. [CrossRef]

16. Jang, I.C.; Oh, S.J.; Seo, J.S.; Choi, W.-B.; Song, S.I.; Kim, C.H.; Kim, Y.S.; Seo, H.S.; Choi, Y.D.; Nahm, B.H.; et al. Expression of a bifunctional fusion of the Escherichia coli genes for trehalose-6-phosphate synthase and trehalose-6-phosphate phosphatase in transgenic rice plants increases trehalose accumulation and abiotic stress tolerance without stunting growth. Plant Physiol. 2003, 2, 516-524. [CrossRef] [PubMed]

17. Jia, W.L.; Hu, Y.L.; Zhang, Y.Q.; Yang, L.L.; Lin, Z.P.; Wu, Q. Transformation of trehalose synthase gene (TPS Gene) into Perennial Ryegrass and identification of drought tolerance. Mol. Plant Breed. 2007, 5, 27-31.

18. Guo, B.; Hu, L.; He, X.; Chen, X.M.; Jiang, X.N. Trehalose-6-phosphate synthase transgenic tobacco enhanced tolerance to salt stress. Chin. Bull. Bot. 2008, 25, 41-49.

19. Zhou, B.H. Cloning and Functional Characterization of the Trehalose-6-Phosphate Synthase Gene Family in Hevea Brasiliensis; Hainan University: Hainan, China, 2017. 
20. Zhang, Y.Q.; Dong, C.L.; Yang, L.L.; Liang, G.M.; Li, J.; Yang, R.; Chang, J.Z.; Zhao, Q.H.; Zhang, M.Y. Study on transformation of trehalose synthase gene tps to maize and their drought resistance. J. Shanxi Agric. Sci. 2016, 44, 1-4.

21. Choi, Y.; Cho, K.W.; Jeong, K.; Jung, S. Molecular dynamics simulations of trehalose as a 'dynamic reducer' for solvent water molecules in the hydration shell. Carbohydr. Res. 2006, 341, 1020-1028. [CrossRef]

22. Zhang, Y.H.; Ji, B.P.; Ling, P.X.; Meng, Y. Protective effects and mechanisms oftrehalose and hyaluronic acid on membrane lipid bilayer. Food Sci. 2007, 28, 31-37.

23. Wang, Z.H.; Kong, D.J.; Chen, L.L.; Wu, C.; Chen, H.; Yang, Z.X.; Wei, K.S.; Lin, Y.C. Effects of exogenous trehalose on chlorophyll metabolism and chloroplast development under low nitrogen condition. J. South. Agric. 2019, 50, 1191-1196.

24. Lin, Y.C.; Zhang, J.; Gao, W.; Chen, Y.; Li, H.; Lawlor, D.W.; Paul, M.J.; Pan, W. Exogenous trehalose improves growth under limiting nitrogen through upregulation of nitrogen metabolism. BMC Plant Biol. 2017, 17, 247. [CrossRef] [PubMed]

25. Jing, E.E. Effects of Choline Chloride and Trehalose on the Growth and Development of Wheat under Low Temperature Conditions; Henan Agricultural University: Zhengzhou, China, 2018.

26. Xie, D.W. Analysis on Gene Expression Profile and Trehalose Gene Family in Winter Wheat under Low Temperature; Northeast Agricultural University: Harbin, China, 2014.

27. Liu, X. Physiological Effects of Exogenous Treha Lose on Chilling Tolerance of Roots of Maize Seedlings; Northeast Agricultural University: Harbin, China, 2018.

28. Long, Y.L. Analysis of Gene Expression Profile in Diploidy and Autotetraploidy Watermelon and Preliminary Study on the Mechanism of Trehalose Resistance; Hainan University: Haikou, China, 2017.

29. Ye, Y.X.; Lu, D.L.; Wang, F.B.; Chen, X.H.; Qi, M.Y.; He, R.; Lu, W.P. Effects of exogenous trehalose on physiological characteristics in waxy maize seedlings under drought stress. J. Maize Sci. 2020, 28, 80-86.

30. Wang, W.J.; Zhang, L.; Yu, M.F.; Wang, P.T. Research progress of trehalose in regulating plant response to abiotic stress. Mol. Plant Breed. 2020, 18, 3433-3440.

31. Ding, S.H. Effect of Exogenous Trehalose on Salt Tolerance of Wheat; Shandong Normal University: Jinan, China, 2001.

32. Liu, F.Z.; Wang, N. Effects of exogenous trehalose on growth of Glycyrrhiza uralensis seedlings and total flavonoid content under salt stress. Chin. Tradit. Herb. Drugs 2020, 51, 6345-6353.

33. Yan, D.L.; Zheng, B.S. Effects of soaking seeds in trehalose on physiological characteristics of wheat Yangmai-19 under salt stress. Acta Agric. Zhejiangensis 2016, 28, 1271-1276.

34. Hu, H.F. The effect of exogenous trehalose on cold resistance of cucumber seedlings. North. Hortic. 2008, 2, 11-13.

35. Hu, H.F.; Ma, Y.H. A study on exgenous trehalose improving droughty resistance of cucumber. J. Shenyang Agric. Univ. 2008, 39, 83-85.

36. Li, J.G.; Pu, L.J.; Zhu, M.; Zhang, R.S. The present situation and hot issues in the salt-affected soil research. Acta Geogr. Sinaca 2012, 67, 1233-1245.

37. Vincent, D.; Ergül, A.; Bohlman, M.C.; Tattersall, E.A.R.; Tillett, R.L.; Wheatley, M.D.; Woolsey, R.; Quilici, D.R.; Joets, J.; Schlauch K.; et al. Proteomic analysis reveals differences between Vitis vinifera L. cv. Chardonnay and cv. Cabernet Sauvignon and their responses to water deficit and salinity. J. Exp. Bot. 2007, 58, 1873-1892. [CrossRef]

38. Wang, J.L.; Huang, X.J.; Zhong, T.Y.; Chen, Z.G. Review on sustainable utilization of salt-affected land. Acta Geogr. Sinaca 2011, 66, 673-684.

39. Zhang, K.; Li, M.N.; Cao, S.H.; Sun, Y. The research advances of molecular mechanisms of plant in responding to salt stress. Acta Agrestia Sin. 2017, 25, 226-235. [CrossRef]

40. Chen, J.; Lin, Q.F. Progress on salt tolerance physiology and mechanism of plants. Nat. Sci. J. Hainan Univ. 2003, 21, 177-182.

41. Yang, S.H.; Ji, J.; Wang, G.; Song, Y.J. Research progress on the effects of salt stress on plants. Mol. Plant Breed. 2006, 4, 139-142.

42. Munns, R. Physiological processes limiting plant growth in saline soils: Some dogmas and hypotheses. Plant Cell Environ. 2010, 16, 15-24. [CrossRef]

43. Zhu, Y.C.; Sun, D.X.; Liu, J.P.; Sun, X.W. Effects of chitosan oligosaccharides on watermelon seedlings with different salt tolerance under $\mathrm{NaCl}$ stress. J. Fruit Sci. 2020, 37, 866-874.

44. Yang, H.L.; Liu, Y.J.; Wang, C.L.; Zeng, Q.Y.; Natarajan, K. Molecular Evolution of Trehalose-6-Phosphate Synthase (TPS) Gene Family in Populus, Arabidopsis and Rice. PLoS ONE 2012, 7, e42438. [CrossRef]

45. Wang, J. Expression of Duplicated ClR2R3-MYB Genes in Watermelon Response to Low Temperature Stress; Huazhong Agricultural University: Wuhan, China, 2019.

46. He, J.; Gu, X.R.; Wei, C.H.; Yang, X.Z.; Li, H.; Ma, J.X.; Zhang, Y.; Yang, J.Q.; Zhang, X. Identification and expression analysis under abiotic stresses of the bHLH transcription factor gene family in watermelon. Acta Hortic. Sin. 2016, 43, $281-294$.

47. Guo, S.; Zhang, J.; Sun, H.; Salse, J.; Lucas, W.J.; Zhang, H.; Zheng, Y.; Mao, L.; Ren, Y.; Wang, Z. The draft genome of watermelon (Citrullus lanatus) and resequencing of 20 diverse accessions. Nat. Genet. 2013, 45, 51-58. [CrossRef]

48. Hurst, L.D. The Ka/Ks ratio: Diagnosing the form of sequence evolution. Trends Genet. 2002, 18, 486. [CrossRef]

49. Song, J.; Gao, Z.; Huo, X.; Sun, H.; Xu, Y.; Shi, T.; Ni, Z. Genome-wide identification of the auxin response factor (ARF) gene family and expression analysis of its role associated with pistil development in Japanese apricot (Prunus mume Sieb. et Zucc). Acta Physiol. Plant 2015, 37, 145. [CrossRef]

50. Wang, X.; Shi, X.; Hao, B.; Ge, S.; Luo, J. Duplication and DNA segmental loss in the rice genome: Implications for diploidization. New Phytol. 2005, 165, 937-946. [CrossRef] 
51. Lunn, J.E. Gene families and evolution of trehalose metabolism in plants. Funct. Plant Biol. 2007, 34, 550-563. [CrossRef]

52. Ramon, M.; De Smet, I.; Vandesteene, L.; Naudts, M.; Leyman, B.; Van Dijck, P.; Rolland, F.; Beeckman, T.; Thevelein, J.M. Extensive expression regulation and lack of heterologous enzymatic activity of the Class II trehalose metabolism proteins from Arab. Thaliana. Plant Cell Environ. 2009, 32, 1015-1032. [CrossRef]

53. Chary, S.N.; Hicks, G.R.; Choi, Y.G.; Carter, D.; Raikhel, N.V. Trehalose-6-Phosphate Synthase/Phosphatase Regulates Cell Shape and Plant Architecture in Arabidopsis. Plant Physiol. 2008, 146, 97-107. [CrossRef]

54. Vandesteene, L.; Ramon, M.; Roy, K.L.; Dijck, P.V.; Rolland, F. A single active trehalose-6-P synthase (TPS) and a family of putative regulatory TPS-like proteins in Arabidopsis. Mol. Plant 2010, 3, 406-419. [CrossRef]

55. Zang, B.; Li, H.; Li, W.; Deng, X.W.; Wang, X. Analysis of trehalose-6-phosphate synthase (TPS) gene family suggests the formation of TPS complexes in rice. Plant Mol. Biol. 2011, 76, 507-522. [CrossRef]

56. Yeo, E.T.; Kwon, H.B.; Han, S.E.; Lee, J.T.; Ryu, J.C.; Byu, M.O. Genetic engineering of drought resistant potato plants by introduction of the trehalose-6-phosphate synthase (TPS1) gene from Saccharomyces cerevisiae. Mol. Cells 2000, 10, 263-268. [PubMed]

57. Li, H.W.; Zang, B.S.; Deng, X.W.; Wang, X.P. Overexpression of the trehalose-6-phosphate synthase gene OsTPS1 enhances abiotic stress tolerance in rice. Planta 2011, 234, 1007-1018. [CrossRef]

58. Li, Y.; Liu, S.K. Cloning of a TPS gene and analysis of its function in stress tolerance in Puccinellia tenuiflora. Acta Prataculturae Sin. 2015, 24, 99-106.

59. Shi, J.W.; Xu, Y.; Ji, D.H.; CHen, C.S.; Xie, C.T. Cloning and expression analysis of trehalose-6-phosphate synthase (TPS) family genes from Pyropia haitanensis. J. Fish. China 2015, 39, 485-495.

60. Jiang, W. Functional Identification and Diferential Expression Analysis of Trehalose-6-Phosphate Synthase Gene Family in Maize; Sichuan Agricultural University: Yaan, China, 2010.

61. Yuan, G.P.; He, S.S.; Bian, S.X.; Han, X.L.; Liu, K.; Cong, P.H.; Zhang, C.X. Genome-wide identification and expression analysis of major latex protein (MLP) family genes in the apple (Malus domestica Borkh.) genome. Gene 2020, 733, 144275. [CrossRef]

62. Reddy, A.S.N.; Marquez, Y.; Kalyna, M.; Barta, A. Complexity of the alternative splicing landscape in plants. Plant Cell 2013, 25, 3657-3683. [CrossRef]

63. Baek, J.M.; Han, P.; Iandolino, A.; Cook, D.R. Characterization and comparison of intron structure and alternative splicing between Medicago truncatula, Populus trichocarpa, Arabidopsis and rice. Plant Mol. Biol. 2008, 67, 499. [CrossRef]

64. Bartels, D.; Sunkar, R. Drought and salt tolerance in plants. Crit. Rev. Plant Sci. 2005, 24, 23-58. [CrossRef]

65. Hu, X.; Wu, Z.D.; Luo, Z.Y.; Burner, D.M.; Wu, C.W. Genome-Wide Analysis of the Trehalose-6-Phosphate Synthase (TPS) Gene Family and Expression Profiling of ScTPS Genes in Sugarcane. Agronomy 2020, 10, 969. [CrossRef]

66. Wang, Q.; Liu, T.R.; Liu, N.; Xiong, F.; Zhang, S.M.; Dong, L.L. Colning and expression analysis of trehalose 6 phosphate synthase g ene phtps6 from petunia hybrida. Acta Agric. Boreali Occident. Sin. 2019, 28, 273-278.

67. Husen, A.; Iqbal, M.; Aref, I.M. IAA-induced alteration in growth and photosynthesis of pea (Pisum sativum L.) plants grown under salt stress. J. Environ. Biol. 2016, 37, 421-429.

68. Chen, X.Y. Effect of Exogenous Trehalose on Sugar Metabolism Response to Salt Stress in Tomato Seedlings; Tianjin University: Tianjin, China, 2016.

69. Guo, S.G.; Zhao, S.J.; Sun, H.H.; Wang, X.; Wu, S.W.; Lin, T.; Ren, Y.; Gao, L.; Deng, Y.; Zhang, J.; et al. Resequencing of 414 cultivated and wild watermelon accessions identifies selection for fruit quality traits. Nat. Genet. 2019, 51, 1616-1623. [CrossRef]

70. Artimo, P.; Jonnalagedda, M.; Arnold, K.; Baratin, D.; Csardi, G.; Decastroe, E.; Duvaud, S.; Flege, L.V.; Fortier, A.; Gasteiger, E. ExPASy: SIB bioinformatics resource portal. Nucleic Acids Res. 2012, 40, 597-603. [CrossRef] [PubMed]

71. Chou, K.C.; Shen, H.B. Cell-PLoc 2.0: An improved package of web-servers for predicting subcellular localization of proteins in various organisms. Nat. Sci. 2010, 2, 1090-1103. [CrossRef]

72. Chen, C.J.; Chen, H.; Zhang, Y.; Thomas, H.R.; Frank, M.H.; He, Y.H.; Xia, R. TBtools: An Integrative Toolkit Developed for Interactive Analyses of Big Biological Data. Mol. Plant 2020, 13, 1194-1202. [CrossRef]

73. Thompson, J.D.; Gibson, T.J.; Higgins, D.G. Multiple Sequence Alignment Using ClustalW and ClustalX. Chapter 2, Unit 2.3. Curr. Protoc. Bioinform. 2002, 1, 2-3.

74. Sudhir, K.; Glen, S.; Koichiro, T. MEGA7: Molecular Evolutionary Genetics Analysis Version 7.0 for Bigger Datasets. Mol. Biol. Evol. 2016, 33, 1870-1874.

75. Bailey, T.L.; Mikael, B.; Buske, F.A.; Martin, F.; Grant, C.E.; Luca, C.; Ren, J.; Li, W.W.; Noble, W.S. MEME Suite: Tools for motif discovery and searching. Nucleic Acids Res. 2009, 37, 202-208. [CrossRef]

76. Kenneth, J.L.; Thomas, D.S. Analysis of relative gene expression data using real-time quantitative PCR and the $2^{-\Delta \Delta C T}$ method. Methods 2002, 25, 402-408.

77. Clough, S.J.; Bent, A.F. Floral dip: A simplified method for Agrobacterium-mediated transformation of Arab. Thaliana Plant J. 1998, 16, 735-743. [CrossRef] 